certain number of patients, being moribund at the time of their arrival and beyond the reach of any treatment, no antitoxin was given."

I am, Sirs, yours faithfully,

Iansfield-street, W., July 21st, 1896 . LENToX Browne.

\section{THE HEALTH OF MARGATE.}

To the Editors of THE LANCET.

SIRS,-It having come to my knowledge that a rumour has been circulated that several cases of typhoid fever have recently occurred in Margate I shall be obliged if you will kindly give me the opportunity to contradict it. The date of the last notification of this disease in this borough was over two months ago-viz., on May 15th, 1896. This, moreover, was an isolated case, no other having occurred about the same time, and it was immediately removed to our infectious diseases hospital, which is sitnated about two and a half miles out of the town.

I am, Sirs, yours very truly,

Margate, July 21st, 1896.

A. W. SCATLIFF Medical Officer of Health.

\section{THE INVERNESS MEDICAL SOCIE'TY.}

To the Editors of THE LANCET.

StRS, - In THE LANCET of July 18th your Inverness correspondent, reporting the proceedings of the Inverness Medical Society, has the following: "The club question came up for discussion at several meetings and the members were unanimous in refusing to undertake club work unless the scale of rates were in accordance with that suggested by the society. The clubs did not see their way to agree to this arrangement and the medical officers resigned. The clubs in town joined together and advertised for a medical officer to undertake the work at their terms. Unfortunately for the credit of the profession a medical gentleman, Dr. Callender, formerly of Leeds, accepted the position, thus frustrating the efforts of the society in their endeavour to place the relations of the medical practitioners in Inverness and the clubs on a better financial basis than they had been hitherto." These sentences, in so far as they relate to the united clubs in Inverness and their medical officer, are false. The united clubs gave up their old terms and adopted simpliciter the scale of rates suggested by the medical society. The clubs unanimously elected $\mathrm{Dr}$. Callender as their medical officer, and he holds the appointment at the scale of rates suggested by the medical society. Dr. Moir, secretary to the Inverness Medical Society, knew these facts six months ago. "Unfortunately for the credit of the medical profession" your Inverness correspondent has given a statement to you which (at any time during the last six months he had ample opportunity to find out) is false.

\section{We are, Sirs, yours truly,}

J. CALLENDER,

Medical Officer ;

JAMES CORNET,

Inverness, July 20th, 1896.

Hon. Sec. Committee of Combined Clubs.

\section{"A UNIQUE EXPERIENCE IN ETHER ADMINISTRATION."}

To the Editors of THE LANCET.

SIRS,-I was interested in reading the report of this case in THE LANCEN of July 11th, as I have been noticing for the last two years how little ether need be used to keep a patient fully anæsthetised. In an article on ether administration which appeared in the Bristol Medico-Chirurgical Journal of September, 1895, I stated that nearly all patients when once fully under with ether could be kept so with the indicator of Clover's apparatus midway between " 0 " and "1." I never find it necessary to keep the indicator at " 2 ," as some books recommend, and I frequently succeed in maintaining complete anæsthesia for more than half an hour at a time with the indicator at "0." I quite agree with Dr. Carter that such cases show "how much more ether is frequently given than is necessary."

I am, Sirs, yours truly,

J. FREEMAN, F.R.C.S. Ed.

Bristol, Juily 19th, 1896 .

\section{"THE REMUNERATION OF MEDICAL MIEN."} To the Editors of THE LANCET.

SIRS, - The inadequate remuneration of medical men depends, I think, on two sets of causes: (1) those acting from without and which in the present state of things seem incapable of amelioration; and (2) those acting from within, from the conduct of medical men themselves. Among the first set of causes of ill-remuneration may be mentioned overcrowding of the profession, the multitudinous array of pestilent quacks, the ignoble army of patent medicine vendors with their cmnipotent wares, and the counterprescribing druggists mentioned by " $\mathrm{H}$. C. L." in THE LANCET of July 4th. The district in which I live has lately been infested by quack cataract-without-operation curers, magic belt bouncers, and the ubiquitous Esculapii of the Sequah type. With regard to patent medicines, bold advertisement and the fact of a Government stamp being affixed to each bottle or box account for their huge sale. The public imagine that what is stamped in this way must be genuine. It is astonishing how widespread the use of patent medicines is amongst all classes of the community. There is hardly a household in Great Britain which does not possess a box of magic pills or some other equally beneficent remedy. In the most well-to.do houses I have seen the wellknown electricities of a certain deceased nobleman. An ounce of these costs $3 s .9 d$. - an exorbitant price for pure water. Nothing can put a stop to this scrt of thing except the refusal of newspapers to publish quack advertisements, but these halcyon days can hardly be looked for. Counter prescribing is a serious evil and should be put down with a strong hand, and the most serious aspect of it is that druggists in many cases prescribe without sfeing the "patient" at all. A friend or relative (generally a female) comes to the shop, details the symptoms to the best of ber ability, clutches the remedy, and marches off. Can anything be more dangerous and idiotic? Druggists say that medical men invade their province by making up their own medicines, but they seem to ignore the fact that there is a vast difference between themselves and medical men in the matter of clinical knowledge and the faculty of diagnosing disease When a medical man makes up his medicine he does so with an intelligent and scientific object, which is more than can be said for the druggist, who is simply an empiric, as his medical knowledge is nil. Another favourite device of the ordinary druggist is to make up and advertise stock remedies evolved from his own brain for certain diseases: Quackem's Elixir for Coughs and Colds : invaluable in Bronchitis, \&c. In many of these "chest mixtures" I am afraid there is opium, and the danger of administering these to old people suffering from bronchitis may be imagined. Verily, "fools step in where angels fear to tread." But druggists are not wholly to blame. In these days so many cheap manuals on self-doctoring and newspaper articles on medical subjects are published that the public are beginning to think they can diagnose their own diseases, and they simply apply to the druggist for the remedies recommended in these publications. As to the second set of causes, arising from the conduct of medical men themselves, much might be said, but there is one line of conduct which is becoming commoner every day-i.e., under-cutting one's neighbour in the matter of fees. This, of course, may arise from the terrible struggle for existence, but in many cases it is simply an underhand way of increasing a practice at the expense of a medical brother, as it is done in the case of well-to-do patients every day. What is the remedy for this kind of thing? A universal tariff of minimum charges should be established and every medical man should be bound not to charge less than these. Again, large numbers of medical men are let loose on the public every year who have no idea of medical etiquette or of their duty towards their neighbour, and who will filch a patient by any means, however unfair, and can see no harm in so doing. I think medical students should have special lectures on medical etiquette and their duties to their neighbour, and should give some guarantee before launching into practice that they will faithfully abide, so far as possible, by the rules of honour and probity laid down for their guidance. The status of the profession can also be ameliorated by raising the standard of general knowledge and culture before allowing students to begin their special medical studies. I have said nothing about the harm done 
to the profession by abuse of hospitals, general and special, and by clubs of all kinds enfolding rich and poor in their embrace, as they are only too well known. Apologising for the length of this epistle,

$$
\begin{aligned}
& \text { I remain, Sirs, faithfully yours, } \\
& \text { July 10th, } 1896 .
\end{aligned}
$$

\section{THE OPICM QUESTION IN INDIA.}

\section{To the Editors of THE LAXCET.}

Sies, - I crave your permission to discuss briefly the conclusions arrired at by the Royal Commission of 1893-94 on the still unsettled opium question, more especially in their relation to the teachings of modern medical science. Something towards the fuller instruction of public opinion has undoubtedly been done by the Commission, and something towards reform in regulating the use of opium. For these results and for the deliberate care which has characterised all its work I trust the public and the profession are not unthankful. We must all note with satisfaction that as regards opium smoking the findings of the Commission have induced the Indian Government to adopt a resolution of the most wholesome character refusing to license shops where opium is sold for smoking. By this decision a powerful check will be placed upon the use of the drug in its most alluring form. Private smoking will not, indeed, be probibited, but the temptation which assails the poorer classes, who are in India the most addicted to the opium pipe, will be greatly weakened. Opium smoking possesses no special therapeutic value. It represents the wanton and self-indulgent aspect of the opium habit, and its mischievons effects have often been exposed. The members of the Commission, feeling themselves to be supported by the great bulk of medical and of educated native opinion, have wisely resolved not to favour this pernicious form of luxury. I observe with regret that they have not been equally ready to perceive that the same drug when used with like freedom in other forms is also fruitful of injury to its credulous victims. They have obtained conclusive proof that it is widely employed as a febrifuge in malaria, a stimulant and restorative, and, it may be added, an aphrodisiac after middle life. It may well be doubted if a medical practitioner would recommend its employment for any one of these purposes unless nnder exceptional conditions and in the presence of actual illness. Its supposed efficacy as a preventive, or a remedy against, malaria will not bear the test of comparison with the results of modern scientific discovery. As a restorative its value is greatest in the aged, but this effect is for many persons largely discounted by resulting disturbances of digestion which tell their own tale in general feebleness and inanition. I must, therefore, confess my inability to perceive any justification for the practice of opium eating, nor can I recognise its true position as other than that of a powerful poison differing essentially and greatly both in kind and degree of action from any of the stimulant and restorative substances now in ordinary use upon our tables and as, being such, useful only for the temporary purposes of instructed medical treatment. There are, especially in India, obvious dangers connected with the free sale of opiates. There is the danger of suicide where a means of release from the sorrows of life is so easily obtainable. From statistics of the deaths by poison in the municipal area of Calcutta during the year ending June 1st, 1894, 846 per cent. (all suicides) were due to opium. When the almost necessarily defective character of registration statistics in other parts of India and the wide prevalence of the opium babit are considered it cannot surely be doubted that a high proportion of deaths by opiumpoisoning holds in other parts of that country besides Calcutta. Infants, too, are reported as being among the sufferers. While for the reason just given one need not expect to find any exact data bearing upon this branch of the subject, too much is known of accidents caused by the overdrugging of infants to question its pernicious effects in a country where opiates are commonly given by native nurses, on their own responsibility, merely to quiet the children. One can, of course. understand and even sympathise with the difficulties of a Grovernment engaged in the introduction of reforms among a population blindly prejudiced in maintaining a favourite indulgence. To some extent this description will apply to the people inhabiting the opium-growing districts of India. At the same time I must also hope that the Indian authorities will see the necessity for discouraging and restricting by every possible means the increase of a babit which, as being a habit, is hurtful whether it finds its modus operandi by swallowing or inhalation. As a first step in this direction I woulc like to see a more discriminating sense of the relation between diseases and their remedies than that which has guided the Opium Commission in their qualified approval of the opium habit as a form of self-doctoring

I am, Sirs, yours faithfully,

July 6th, 1896

\section{BIRMINGHAM.}

(FroM OUB OWN CORRESPONDENT.)

\section{Employment of Epileptics.}

AT a recent meeting of the board of guardians the report of the Infirmary Committee was receired containing some important recommendations upon the employment of epileptic inmates. It was suggested that industrial trainers be obtained to teach boot-making, tailoring, basket-making, sc. The systematic and active employment of this class of imbeciles demands consideration not only in providing interest and occupation, but as an element in the treatment of such patients. However remote the chance of cure may be in many instances, the routine of daily life may lead to more contentment and happiness in the duties engaged. In some cases also expenses may be aroided in establishment charges by work being done by those whose life has to be spent within the workhouse home.

Birmingham and Mialand Ey e Hospital.

The annual meeting of this institution was held on the 16 th inst., the Lord Mayor being in the chair. The report showed the receipt of $£ 600$ from the Hospital Saturday collection and annual subscriptions amounting to $\$ 28687 \mathrm{~s} .6 \mathrm{~d}$, a small decrease as compared with the previous year. Under the head of legacies $£ 56319$ s. had been received. The expenditure had materially increased owing to the opening of an additional wing, the total being $£ 6137$ odd, exclusively of what had been spent upon the building of the new wing, as compared with $\$ 4831$ odd last year; and 5898 17s. 3d. for spectacles and artificial eyes, as against $£ 8402 s$. $6 a$. in 1895. The total number of patients treated was 31,682 , showing an increase of 43 in-patients and 2912 out-patients for the year. From this it will be seen that a vast amount of work is done at this hospital, the popularity of which is a prominent factor in the support it receives.

\section{Children's Holiday Home.}

Thanks to the generosity of Mr. and Mrs. George Cadbury, in connexion with the Sunday-School Union, a pleasing country residence has been placed at the disposal of the committee. The home provides accommodation for fifteen children, is fully equipped by the donors, and admirably situated with every facility for comfort and fresh air. To the many provisions made for poor children this addition is onc which commends itself to the appreciation of those interested in the young of this large city. Waifs and strays, crippled children, convalescent children, and many others will, no doubt, enjoy the opportunities given to them of making their lives brighter and more bappy.

\section{General Institution for the Blind.}

At the recent annual meeting it was stated that the number of blind persons directly benefited by this institution. during the past year was 488 , an increase of 20 orer the previous year. The inspector's report was read, in which it was observed that the provision for manual instruction was not surpassed by any institution. The amount of the Government grant was £294 8s. 9d. Training in handicrafts has received special attention and clay modelling has beec introduced. The committee stated that they would like to introduce the "Saxon system" of keeping up a permanent connexion between the institution and the old pupils, bot do not feel justified in doing so unless special funds ave forthcoming. The year's work had resulted in an adverse balance of $£ 770$, entailing a draw upon the legacy and investment account. Various rotes of thanks were passed to the president, Lord Calthorpe, and others.

Hospital Saturday.

The expectations of the committee have been realised in 